\title{
Risk factors for some non-communicable health conditions in zoo workers in Pinnawela elephant orphanage, Sri Lanka
}

DOI: $10.46932 /$ sfjdv3n1-116

Received in: Jan 30st, 2021

Accepted in: Feb 1th, 2022

\author{
Weththewa Kankanamge Sanuka Malshitha Weththewa \\ Bachelor of Veterinary Science \\ "Dharmika" Siyambalawewa, Galwela, Sri Lanka \\ E-mail: sanukamalshi@gmail.com
}

\section{Liyanage Malith Eranda Madduma}

Masters of Veterinary Science

Pinnawela Zoological Garden, Pinnawela, Sri Lanka

E-mail: malithliyanageliyanage@gmail.com

\section{Bandaranayake Liyanarachchige Dushyanthi Renuka Munasinghe \\ Masters of Veterinary Science \\ Department of Zoological gardens, Dehiwela, Sri Lanka \\ E-mail: nauchali@yahoo.com}

\section{Malinga Lekamge Prasad}

Bachelor of Veterinary Science

Ihala Rukmale, Narammala, Sri Lanka

E-mail: prasadmalinga924@gmail.com

\section{Dangolla Ashoka \\ $\mathrm{PhD}$}

Department of Veterinary Clinical Science

University of Peradeniya, Peradeniya, Sri Lanka

Adress: Galaha Rd, 20400, Sri Lanka

E-mail: adangolla@gmail.com

\begin{abstract}
A medical clinic to examine the risk factors for some non-communicable disease (NCD)s was held for zoo workers with permission from the management within Pinnawela elephant orphanage (PEO). Resulting information was compared between those who work with (E) and those do not work closely with elephants (NE). The medical staff comprised of 3 doctors, 3 nurses 2 attendants and 2 laborers. A questionnaire was administered as and when each participant zoo worker was examined. Those with health issues requiring further medical attention were referred to the general hospital $8 \mathrm{~km}$ away. A total work force in PEO is around 90 and 82 of them participated in the clinic, 22 were from E while 60 were from NE group. Overall body mass index (BMI) of participants indicated 4 participants to be obese, 36 to be overweight and 3 to be underweight, most of them from NE group. Altogether, 18(18/78) had elevated systolic blood pressure out of which 14 (14/82) were from NE. A total of 6 had elevated diastolic blood pressure out of which 5 were from NE group. Vision and hearing appeared not to be serious issues. Alcohol consumption and regular smoking were frequently observed among the NE group. Only one from $\mathrm{E}$ and 8 from NE reported some chronic health condition in them. Overall, 74 workers were not found to be having any of the chronic conditions listed $(73 / 82=91 \%)$ out of which vast majority $(n=20)$ were from
\end{abstract}


E group. Food habits, regular exercise and perhaps social aspects may have contributed to the findings. The E group was apparently healthier compared to those in NE perhaps due to their constant exposure to work related regular exercise. Rapid attention must be paid towards NCD situation in zoo workers, if the work force must be maintained healthy.

Keywords: pinnawela, elephant keepers, non communicable diseases, body mass index, sri lanka.

\section{INTRODUCTION}

Contribution by non-communicable diseases (NCD) towards global health burden is high among which cardiovascular disease, cancer, and chronic respiratory disease dominate (Beaglehole et al., 2007). Death from NCD are expected to increase by 17\% over the period 2005- 2015 (World Health Statistics, 2008) accounting for $69 \%$ of global deaths by 2030 (Mathers and Loncar, 2006). Body Mass Index (BMI) calculated on normal weight range (BMI 25.0-29.9 kg/m2) provides a good idea about health. Global annual deaths due to overweight and obesity; elevated cholesterol levels and high blood pressure are on the increase (Beaglehole et al., 2007). Currently observed high prevalence of the NCD in India (Anand et al., 2007) could possibly be due to increase in frequency of risk factors (Thankappan et al., 2010). Sri Lankan school children, must be taught that the NCD s can be prevented by both avoiding bad life habits and by introducing regular physical exercise (Senadheera et al., 2018).

Sri Lanka has a captive elephant population of 112 (Fernando, 2011). Their keepers are compelled to, at least walk with their elephants for reasonable distances daily, and therefore, may be exposed to regular exercise, though their living habits could be unhealthy (Jayawardena et al., 2011). Unsatisfactory oral health and chest conditions appear to be frequent among captive elephant keepers in Sri Lanka (Jayawardena et al., 2011). However, such health conditions have not been investigated among those who work with elephants in state sector which could be different since they are government workers, follow strict instructions and are possibly better disciplined though their work related stress could be the same. Such stress can keep them at an elevated risk of developing hypertension and diabetes mellitus (Perez et al., 2001).

NCD situation has not been studied in detail among zoo keepers in Sri Lanka. It is important for the zoo administration to make the work force healthier and keep them united to improve their work output. It has been shown that the zoo veterinarians are perhaps more exposed to allergies and infections compared to average population and therefore, safety measures must be adopted to improve their quality of life (Hill et al., 1998). The objective of this study was to examine status of some NCDs among the zoo workers in PEO and to compare them between two categories of workers namely, elephant related (E) and those who do not work with elephants (NE). 


\section{MATERIALS AND METHODS}

In October 2018, a detailed questionnaire was administered with zoo workers, with permission from administration, during a health clinic held within PEO. The health team included, 3 medical officers, 3 nurses, and 4 health attendants. Questionnaire included age, date of birth, occupation and civil stats. The height and weight of workers were measured in clinic and smoking and liquor consumption details were filled by the workers themselves into the questionnaire format. The health team checked blood pressure, random blood sugar level, examined cardio pulmonary system and vision and hearing of the participants. Presence or absence of chronic health conditions in the past namely, heart attacks, strokes, cancer, kidney diseases, hypertension, diabetes mellitus, chronic respiratory diseases and bronchial asthma in participants and their family members were in the questionnaire. The BMI was calculated using available information. The data was compared between those who work with elephants (E) and those who do not work with elephants (NE), when appropriate.

\section{RESULTS}

PEO has around 90 workers out of which 82 participated in the health clinic. Most participants were males $(67 / 82=82 \%)$, were not working with elephants $(60 / 82=73 \%)$ and therefore were office staff and most were married $(64 / 80=80 \%)$. Table 1 shows the mean and median age, height, weight, BMI and blood pressure of the participants attended to the medical clinic.

Table - Mean, median, range and normal values of age, height, weight, body mass index, random blood glucose, systolic and diastolic blood pressure of the 82 workers at Pinnawela Elephant orphanage

\begin{tabular}{|l|l|l|l|l|l|}
\hline & & & Range & Normal \\
\cline { 4 - 5 } Category & Mean & Median & Min & Max & value/Range \\
\hline Age & 37.54 & 38 & 19 & 59 & \\
Height & 162.9 & 164 & 123 & 181 & \\
Weight & 66.1 & 65.5 & 43 & 93 & \\
Body Mass Index (BMI) & 24.8 & 24.9 & 16.6 & 36.2 & $18.5-24.9$ \\
Random blood sugar level & 105.9 & 102 & 71 & 222 & $<200$ \\
Systolic blood pressure & 120.03 & 120 & 100 & 160 & 120 \\
Diastolic blood pressure & 78.6 & 80 & 70 & 100 & 80 \\
\hline
\end{tabular}

BMI of only 39 (39/82=47.6\%) individuals were normal (15 E and 24 NE groups), 36 (34 from NE group) were higher and 7 were below normal. Random blood sugar level was higher than normal only in 2 individuals and both were from NE group. Median systolic blood pressure was higher than normal in 18/78=23\% (14 from NE) and median diastolic blood pressure was higher in 8\% (6/78: 5 from NE). From E group, defective vision $(1 / 21=5 \%)$ and heart problems $(6 / 21=29 \%)$ were reported while from NE group, vision problems $(7 / 60=12 \%)$, hearing problems $(1 / 60=2 \%)$, thyroid problems $(1 / 60=2 \%)$ and heart problems $(14 / 60=23 \%)$ were identified. Only a total of 5 from E and 9 from NE, did not report any of the 
above conditions $(5 / 21=23 \%$ and $9 / 60=15 \%$, respectively). From among the known risk factors for NCD s, smoking and alcohol consumption; 5 from E were smoking $(5 / 21=23 \%)$ while 5 from E consume alcohol $(5 / 21=23 \%)$. Four (4) from NE smoke $(4 / 60=7 \%)$ while 9 from NE consume alcohol $(9 / 60=15 \%)$.

A total of 74 participants, did not report any chronic condition while 1 from $\mathrm{E}$ and 8 from NE reported such chronic conditions. Seven participants $(7 / 82=9 \%)$ reported more than one such chronic condition listed and all of them were from NE group. A total of 10 families of E group (10/21), about half, reported chronic health conditions and 2 families reported more than one such chronic condition. In families of NE group, 44 reported some chronic condition (44/60=73\%). Family members of 14 from NE group reported more than one such chronic health condition.

\section{DISCUSSION}

It is clear that healthy BMI and normal random blood sugar, hyper tension, hypotension and chronic health conditions are less frequently reported in elephant related working group (E). The WHO recommended BMI values lie between 18.5-24.9, while that of underweight, overweight and obese are $<18.5,25-29.9$ and $>30$ respectively (Lim et al., 2017). Though most clinic participants were expectedly within the normal BMI range, 3 were underweight, 36 were overweight and 4 were obese. Such situations keep the workers at a higher risk of developing several NCD s. It is well known that working with stressful conditions lead to NCD s (Perez et al., 2001) which could lead to an unhealthy life style and due to same situation such individuals tend to get easily addicted to bad life habits (Jayawardena et al., 2014; Jayawardena at al., 2011). It is possible that captive elephant keepers are compelled to carry out their duties despite bad weather conditions, and may not even have meals on time, which could keep them at an elevated risk of developing NCDs. However, in the government working set up within the PEO, this appears not to be the case. It is also possible that the NE group, mostly office workers, do not get sufficient physical exercise, which lead to observed frequent reporting of risk factors for development of NCD. Earlier studies, however, have clearly shown the urgent need of increasing leisure activity among Sri Lankans due to rapid urbanization (De Silva Welianga et al., 2016).

Though risk factors for potential development of NCDs need attention in PEO, more attention must be paid towards NE group. Unacceptable life style, food pattern and lack of physical exercise could be the main reasons for such elevated risks. In Sri Lanka, though health can be considered satisfactory, issues related to life styles, societal and economic crisis can still be seen (Jayasekara and Shultz, 2007). High BMI, stress and diabetes independently are associated with hypertension and having family members with cardiac conditions keep such individuals at higher risk for developing the same (Perez et al., 2001). Even though evidence herein need more information to support for confirmation, it is time that these 
aspects of workers at PEO are attended before they develop into serious levels. Alcohol and smoke which are long time known risk factors (Parry et al., 2011) for NCD and appear to be not uncommon within the PEO workers, particularly among NE group. Such risk factors however, are common among captive elephant keepers in private sector in Sri Lanka (Jayawardena et al., 2014; Jayawardena et al., 2011, Dassanayake et al., 2011). It is also good to conduct a educational workshops with a practical guide on better living, good exercise and good habits within the zoo so that the workers could lead a healthier life. Nonetheless, occupational hazards have not been much studied in Sri Lanka (Jayawardana and Abeysena, 2009).

Though vision and hearing were not serious problems, the NE group and their family members need attention in this regard. The unhealthy family background of NE workers may also have contributed to observed situation, just as it has been shown in a well-planned study in Malasia (Hazreen et al., 2014). The families of NE group, most of who belong to middle income class may not have sufficient regular exercise, in their daily routines. 


\section{REFERENCES}

Anand K, Shah B, Yadav K, Singh R, Mathur P, Paul E, and Kapoor SK . (2007). Are the urban poor vulnerable to non-communicable diseases? A survey of risk factors for non-communicable diseases in urban slums of Faridabad. National Medical Journal of India 20 (3): 115-20.

Beaglehole R, Ebrahim S, Reddy S, Voûte J and Leeder S. (2007). Prevention of chronic diseases: A call to action. Lancet 370 (9605): 2152-57.

Dassanayake DLB, Jayawardena KLTD, Siribaddana A and Dangolla A. (2011). Prevalence of Tuberculosis in keepers of captive elephants in Sri Lanka. Proceedings of the Peradeniya University Research Sessions, Sri Lanka, Vol. 16, 24.

De Silva Weliange S, Fernando D, Gunatilake J. Pattern of Physical Activity Among Sri Lankan Adults in the District of Colombo: A Cross-sectional Study. Asia Pac J Public Health. 2016 Nov;28(8):725-736. doi: 10.1177/1010539516660191. Epub 2016 Jul 27. PMID: 27469309.

Fernando P. (2011). Current Status of Asian Elephants in Myanmar. Gajah 35: 76-86.

Hazreen MA, Su TT, Jalaludin MY, Dahlui M, Chinna K, Ismail M, Murray L, Cantwell M, Sadat NA. (2014). An exploratory study on risk factors for chronic non-communicable diseases among adolescents in Malaysia: Overview of the Malaysian health and adolescents longitudinal research team study (The MyHeART Study). BMC Public Health 14 (Suppl 3): 1-10.

Hill DJ, Langley RL , and Morrow WM. (1998). Occupational injuries and illnesses reported by Zoo Veterinarians in the United States. Journal of Zoo and Wildlife Medicine 29(4): 371-385.

Jayasekara R and Schultz TJ. (2007). Health status, trends, and issues in Sri Lanka. Nursing and Health Sciences 9(3):228-33. DOI:10.1111/j.1442-2018.2007.00328.x

Jayawardana P and Abeysena C. (2009). Respiratory Health of Welders in a Container Yard, Sri Lanka. Occupational Medicine 59 (4): 226-29.

Jayawardena KLTD, Bannehakka BMHSK and Dangolla A. (2014). Health of captive elephant keepers in Sri Lanka. Proceedings of Annual Research Sessions, University of Peradeniya, Vol 18, 294.

Jayawardena KLTD, Dissanayaka D and Dangolla A. (2011). Biochemical markers in liver injury in keepers of captive elephants in Sri Lanka. Peradeniya University Research Sessions. Page 114.

Lim JUK, Lee JH, Kim JS, Hwang YI, Kim TH, Lim SY, Yoo KH, Jung KS, Kim YK, and Rhee CK. (2017). Comparison of World Health Organization and Asia-Pacific Body Mass Index Classifications in COPD Patients. International Journal of COPD 12: 2465-75.

Mathers CD, and Loncar D. (2006). Projections of Global Mortality and Burden of Disease from 2002 to 2030. PLoS Medicine 3 (11): 20 11-30.

Parry CD, Patra J, Rehm J. (2011). Alcohol consumption and non-communicable diseases: epidemiology and policy implications. PMID: 21819471, Oct 106 (10), 1718-24. PMCID: PMC3174337, DOI: $10.1111 / \mathrm{j} .1360-0443.2011 .03605 . \mathrm{x}$

Perez LH, Gutierrez LA, Vioque J, and Torres Y. (2001). Relation between overweight, diabetes, stress 
and hypertension: A Case-Control study in Yarumal - Antioquia, Colombia. European Journal of Epidemiology. 17 (3): 275-80.

Senadheera SSPA, Bandara JPRSR, Sewwandi L and Fernando N. (2018). Knowledge on noncommunicable diseases among advanced level school children in the Anuradhapura municipal council area in Sri Lanka.Sri Lanka Journal of Medicine, 27(1), pp.37-46. DOI: http://doi.org/10.4038/sljm.v27i1.76

Thankappan KR, Shah B, Mathur P, Sarma P, Gopala S, Mini GK, Soman B, Vasan RS (2010). Risk factor profile for chronic non-communicable diseases: Results of a community-based study in Kerala, India. Indian J Med Res 131, 53-63.

World health statistics. (2008). Publications of the World Health Organization can be obtained from WHO Press, World Health Organization, 20 Avenue Appia, 1211 Geneva 27, Switzerland. 